\title{
I mproving patient satisfaction by adding a physician in triage
}

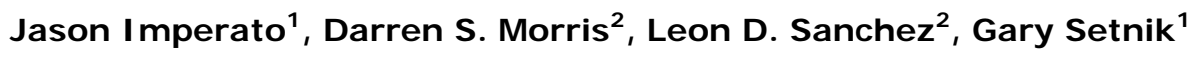 \\ 1. Department of Emergency Medicine, Mount Auburn Hospital, Cambridge, USA. 2. Department of Emergency Medicine, \\ Beth Israel Deaconess Medical Center, Boston, USA.
}

Correspondence: Jason Imperato. Address: Department of Emergency Medicine, Mount Auburn Hospital, 330 Mount Auburn Street, Cambridge, MA 02138, USA. E-mail: jimperat@mah.harvard.edu

Received: June 18, 2013

DOI : $10.5430 /$ jha.v3n1p7

\author{
Accepted: August 11, $2013 \quad$ Online Published: September 4, 2013 \\ URL: http://dx.doi.org/10.5430/jha.v3n1p7
}

\begin{abstract}
Background: The physician in triage (PIT) model has been proposed as a process improvement to help increase efficiency in the Emergency Department setting. However, its effect on patient satisfaction has not been well established.

Methods: An interventional study comparing patient satisfaction scores for the 6-month period before and after implementation of a physician in triage model. In our system an additional attending physician was assigned to triage from 1 p.m. to 9 p.m. daily. Outcome measures were mean scores obtained from respondents to Press Ganey® patient satisfaction surveys for selected questions most likely to be impacted by PIT implementation and those included in the physician section of the survey.

Results: Five hundred and eight respondents seen in the six months before the initiation of the PIT team and 458 respondents in the six months after the system change were included in the study. Improvement was noted in the absolute Press Ganey ${ }^{\circledR}$ scores in the Post-PIT time period across all questions analyzed with statistically significant differences noted for 8 of the 10 questions studied.

Conclusions: Although seemingly small there was a statistically significant improvement in the absolute patient satisfaction scores after adding a physician in triage. Because small gains in absolute scores can result in large improvements on the percentile rank when using Press Ganey ${ }^{\circledR}$ surveys, physician in triage may be of significant benefit to overall patient satisfaction.
\end{abstract}

\section{Key words}

Physician in triage, Patient satisfaction, Triage, Administration, Overcrowding

\section{I ntroduction}

Emergency Department (ED) overcrowding is a growing public health concern in the United States and is associated with increased ambulance diversion, prolonged patient wait times, overall patient dissatisfaction and decreased physician productivity ${ }^{[1-3]}$.

Placing a physician in triage has been one suggested intervention to alleviate ED overcrowding because, in theory, it allows for earlier patient contact with a physician and resultant earlier advanced decision-making. There are only a few 
studies in the literature that have investigated the use of a physician in triage ${ }^{[4-12]}$. The majority of these studies have focused on patient flow metrics for measured outcomes.

Only one previous published abstract by Crane et al. ${ }^{[9]}$ addressed the issue of patient satisfaction after adding a physician to triage. This study compared 84 days when there was a doctor in triage versus 59 days when there was not a doctor in triage. They found that there was not a significant difference in overall Press Ganey ${ }^{\circledR}$ scores between the two groups. Our investigation evaluates the effect of a physician in triage on patient satisfaction as measured by responses to Press Ganey ${ }^{\circledR}$ patient satisfaction surveys with a much longer interventional time period and larger number of surveys analyzed.

\section{Patients and methods}

\subsection{Study design}

This is an interventional study utilizing retrospective data to evaluate the effect of a Physician in Triage (PIT) on patient satisfaction as measured by Press Ganey ${ }^{\circledR}$ patient satisfaction surveys. The study site institutional review board approved the research protocol.

\subsection{Setting}

The facility is a community teaching hospital affiliated with a large academic medical school. The ED is a 23-bed unit that evaluates approximately 36,000 adult and pediatric patients per year with an overall admission rate of about $30 \%$, including a $3 \%$ admission rate to the intensive care unit.

Board-certified Emergency Medicine physicians evaluate all patients, with double coverage for 16 hours and single coverage for eight hours a day. The ED is a teaching facility for Emergency Medicine residents who staff three 9-hour shifts per day as well as Internal Medicine interns who staff two 9-hour shifts per day. There is also a Fast Track area that is staffed by physician assistants under the supervision of an attending physician for 12 hours a day.

\subsection{Intervention}

Prior to the studied intervention, a triage nurse first evaluated ambulatory patients and assigned patients to one of two designated areas of the ED - main ED or Fast Track - depending on the perceived patient acuity. When triage was completed patients were either brought to a bed if space was available or placed in the waiting room if their condition permitted. Once in a room a physician evaluated the patient where decisions about diagnostic studies and treatment were made. A schematic of patient flow prior to the studied intervention is shown in Figure 1. Patients who presented via ambulance generally were evaluated in the main ED without going through standard triage - a process that was unchanged before and after the addition of the physician in triage.

On July 1, 2008 we started a PIT team. During this time period, an additional attending physician was assigned to triage from 1 p.m. to 9 p.m. daily for six consecutive months. All of our attending physicians participated in the triage shifts. Additionally, we reassigned a Registered Nurse (RN) and ED technician from the ED to the triage team to help carry out the triage physician orders.

When patients registered in the department they were first evaluated by a triage nurse who performed a brief assessment, recorded vital signs, and entered past medical history, past surgical history, medications, allergies, and social history into our computerized documentation system. The function of this nurse was the same before and after the addition of the physician in triage. 
Patients were then brought to one of two specialized triage-screening rooms for further evaluation by the triage team. The triage physician performed a brief history and examination and then ordered electro-cardiograms, laboratory studies, radiology studies, intravenous fluids, and medications as indicated. These tasks were then performed or initiated by the reassigned nurse and technician who were part of the new triage team.

After evaluation by the triage team, patients were assigned to either the main section of the ED or the fast track area for evaluation and treatment. If space was available patients were moved directly to an ED room; otherwise, condition permitting, they returned to the waiting room while their studies were pending. The triage physician often discharged some lower acuity patients who did not require further testing directly from the screening area.

The triage physician also supervised the physician assistant in the fast track area, answered calls from referring physicians, and managed administrative issues on an as needed basis. Figure 2 depicts patient flow following the addition of the physician in triage.

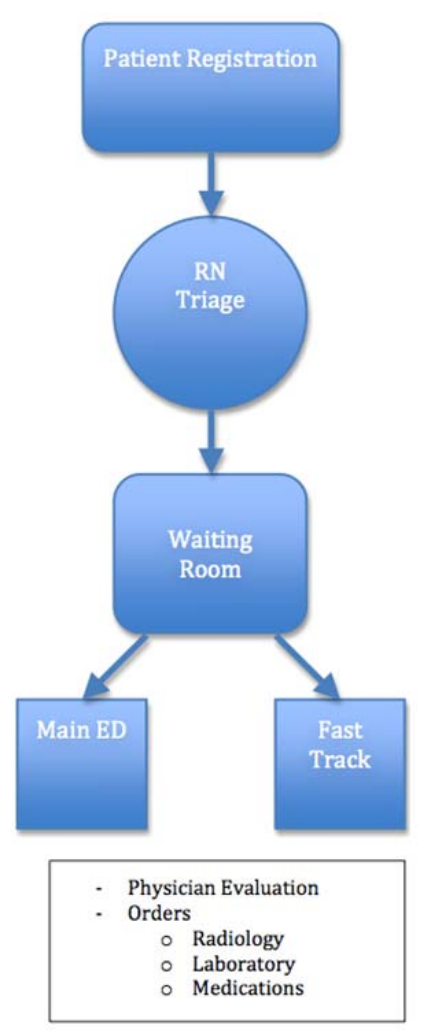

Figure 1. Pre-Intervention: patient flow diagram for ambulatory patients

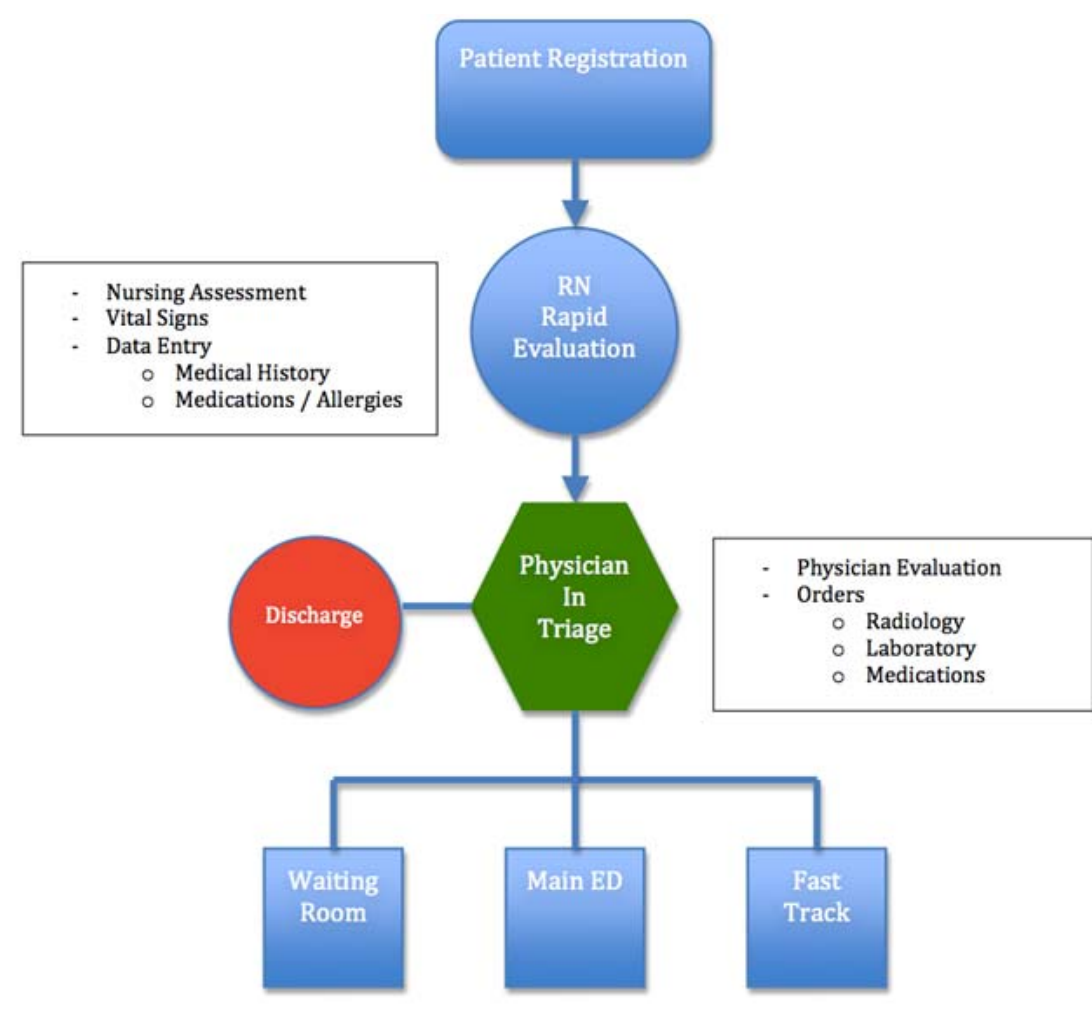

Figure 2. Physician in triage: patient flow diagram for ambulatory patients

\subsection{Selection of participants}

All patients who were sent Press Ganey ${ }^{\circledR}$ patient satisfaction questionnaires between January 1, 2008 and December 31, 2008 were eligible for inclusion in this study. This questionnaire, developed by the international research company Press Ganey ${ }^{\circledR}$, has been used widely in medical centers and research publications and has been designed to meet high standards of reliability and validity ${ }^{[13]}$. The questionnaire is compromised a range of statements related to patient care. For each statement, patients are asked to provide a response on a 5-point Likert scale ranging from very poor to very good. Press Ganey ${ }^{\circledR}$ received all completed questionnaires directly from the patients, collated all data and created a detailed report for 
the hospital administration and the Emergency Department. The report included both absolute scores as well as percentile ranks based on previously assigned comparative groups. After the study period we were given a comprehensive data summary for patients who filled out the questionnaires that were seen in our ED during the specified dates. The overall response rate was $16 \%$ for both groups. The control group included 508 respondents seen in the six months (January 1 , 2008-June 30, 2008) before the initiation of the PIT program. The study group included 458 respondents in the six months (July 1, 2008-December 31, 2008) after the PIT team was in place.

\subsection{Outcome measures}

Data used in the study was obtained through a comprehensive report generated based on responses to Press Ganey® patient satisfaction surveys for patients evaluated during the study period.

We specifically focused on the Press Ganey ${ }^{\circledR}$ questions that were most likely to be impacted by the PIT model and those included in the physician section of the survey. These questions included the following:

- Waiting time to treatment area

- Waiting time to see a doctor

- Doctors courtesy

- Doctor took time to listen

- Doctor informative about treatment

- Doctors concern for comfort

- Informed about delays

- How well pain was controlled

- Overall rating of ER care

- Likelihood of recommending

\subsection{Primary data analysis}

For each question, patients responded with a rating of Very Poor, Poor, Fair, Good, or Very Good, which were converted to scores of one through five, respectively. We calculated the mean score for each question in the control group and PIT group, and also obtained from Press Ganey ${ }^{\circledR}$ the percentile for each question, comparing our scores against all Massachusetts hospitals. We used a standard $t$-test to determine if there were statistical differences in the mean scores for each question analyzed.

\section{Results}

Overall, there were 508 respondents in the control group, and 458 respondents in the PIT group. The demographic data for the respondents is depicted in Table 1. There was not a significant difference in the percentage of respondents in any of the measured demographic categories including shift, gender, or age of patient.

Table 2 depicts the difference in Press Ganey survey results for the Pre-PIT and Post-PIT time periods. There was improvement in the Press Ganey scores in the Post-PIT period across all questions. Statistically significant differences were noted for 8 of the 10 questions investigated.

For the summary question "Overall rating of ED care", respondents ratings improved from 4.22 (standard deviation [SD] = 1.02) before PIT was implemented to $4.38(S D=0.93)$, which despite the small absolute difference in score, represents an improvement from the 6th percentile to the 68th percentile among all Massachusetts hospitals. 
Table 1. Demographic profile of respondents to a press ganey patient satisfaction survey before and after addition of a physician in triage

\begin{tabular}{|c|c|c|c|c|c|}
\hline Characteristics & Control (N) & Control (\%) & PIT (N) & PIT (\%) & $p$-value \\
\hline \multicolumn{6}{|c|}{ Shift } \\
\hline 7a-3p & 248 & 48.8 & 219 & 47.8 & .48 \\
\hline $3 p-11 p$ & 206 & 40.6 & 192 & 41.9 & .41 \\
\hline $11 p-7 a$ & 54 & 10.6 & 47 & 10.3 & .10 \\
\hline Total & 508 & & 458 & & \\
\hline \multicolumn{6}{|c|}{ Gender } \\
\hline Male & 187 & 36.8 & 183 & 40.0 & .38 \\
\hline Female & 321 & 63.2 & 275 & 60.0 & .38 \\
\hline Total & 508 & & 458 & & \\
\hline \multicolumn{6}{|c|}{ Age } \\
\hline $0-17$ years & 23 & 4.5 & 34 & 7.4 & .06 \\
\hline 18 years-34 years & 100 & 19.7 & 93 & 20.3 & .20 \\
\hline 35 years- 49 years & 93 & 18.3 & 98 & 21.4 & .20 \\
\hline 50 years-64 years & 128 & 25.2 & 108 & 23.6 & .24 \\
\hline 65 years-79 years & 105 & 20.7 & 79 & 17.2 & .19 \\
\hline $80+$ years & 59 & 11.6 & 46 & 10.0 & .11 \\
\hline Total & 508 & & 458 & & \\
\hline
\end{tabular}

Abbreviations: PIT, Physician in Triage

Table 2. Press-Ganey satisfaction scores of patients seen before and after the addition of a physician in triage

\begin{tabular}{|c|c|c|c|c|c|c|c|}
\hline \multirow[b]{2}{*}{ Question } & \multicolumn{3}{|c|}{ Control } & \multicolumn{3}{|c|}{ PIT } & \multirow{2}{*}{$\begin{array}{l}\text { Difference in mean } \\
p \text {-value }\end{array}$} \\
\hline & $\mathbf{N}$ & $\begin{array}{l}\text { Score: } \\
\text { Mean (SD) }\end{array}$ & $\%$ & $\mathbf{N}$ & $\begin{array}{l}\text { Score: } \\
\text { Mean (SD) }\end{array}$ & $\%$ & \\
\hline Waiting time to treatment area & 480 & $3.70(1.26)$ & 5 & 437 & $3.97(1.11)$ & 64 & $.001 * *$ \\
\hline Waiting time to see a doctor & 482 & $3.73(1.21)$ & 3 & 441 & $3.91(1.16)$ & 51 & $.019 *$ \\
\hline Doctors courtesy & 498 & $4.42(0.87)$ & 1 & 444 & $4.57(0.76)$ & 57 & $.004 * *$ \\
\hline Doctor took time to listen & 484 & $4.27(0.98)$ & 1 & 435 & $4.48(0.89)$ & 49 & $.001^{* *}$ \\
\hline Doctor informative about treatment & 483 & $4.20(1.09)$ & 1 & 436 & $4.36(0.97)$ & 8 & $.015^{*}$ \\
\hline Doctors concern for comfort & 474 & $4.29(0.99)$ & 3 & 432 & $4.38(0.99)$ & 32 & .170 \\
\hline Informed about delays & 431 & $3.52(1.31)$ & 7 & 406 & $3.74(1.26)$ & 65 & $.018^{*}$ \\
\hline How well pain was controlled & 384 & $3.98(1.15)$ & 1 & 363 & $4.12(1.11)$ & 30 & .082 \\
\hline Overall rating ER care & 488 & $4.22(1.02)$ & 6 & 446 & $4.38(0.93)$ & 68 & $.013^{*}$ \\
\hline Likelihood of recommending & 481 & $4.16(1.17)$ & 9 & 427 & $4.34(1.02)$ & 73 & $.012 *$ \\
\hline
\end{tabular}

Abbreviations: PIT, Physician in Triage; $S D$, Standard deviation

* Statistically significant at the $<0.05$ level

** Statistically significant at the $<0.01$ level

\section{Discussion}

Following the institution of a physician in triage model, we observed a small increase in patient satisfaction absolute scores. There was a statistically significant improvement in 8 of the 10 questions investigated. These differences translate to a remarkable improvement in patient satisfaction percentile rank scores. 
Two questions did not show a statistically significant improvement. These were both related to pain control (doctors' concern for comfort and how well pain was controlled). While our intent was to treat pain earlier, this can be sometimes difficult as, in our model, patients frequently needed to return to the waiting room before moving to the ED and it was sometimes difficult to adequately control pain in this setting. Otherwise, there was a marked improvement across all other questions.

We believe that this is the first comprehensive study of the PIT model to show a significant impact on patient satisfaction. In a published abstract with fewer patient care days and number of surveys, Crane et al. compared 84 days when there was a doctor in triage versus 59 days when there was not a doctor in triage and found that there was not a significant difference in overall Press Ganey ${ }^{\circledR}$ scores when adding a physician to triage ${ }^{[9]}$.

There are a handful of studies that have previously studied the effects of physician triage, but most did not investigate its impact on patient satisfaction and instead focused on patient flow metrics. In a previous study using this same model ${ }^{[12]}$ there was improvement in time to physician evaluation and reduction in length of stay (LOS) and time on diversion following the addition of a physician in triage. In three similar models to the research site, Han et al. ${ }^{[4]}$, Partovi et al. ${ }^{[5]}$, and Holroyd et al. ${ }^{[6]}$ showed a reduction in overall LOS and number of patients leaving without being seen (LWBS). In two studies from the United Kingdom, Terris et al. ${ }^{[7]}$ noted a reduction in number of patients waiting to be seen at any one time utilizing a physician in triage while Subash et al. ${ }^{[10]}$ showed that team triage for three hours a day reduced time to see a doctor and time to radiology during the time of intervention but not for the remainder of the day. Finally, in a study from Hong Kong, Choi et al. ${ }^{[8]}$ showed a reduction in mean waiting time and mean processing time by moving a faculty to triage without additional staffing.

\section{Limitations}

There are several limitations of this study. Most notable is the fact that we used the physician in triage for only eight hours per day. This time period was selected because it represents the busiest hours based on historical volume. The data collected, however, was obtained using Press Ganey ${ }^{\circledR}$ surveys for 24 hours of patient care. As a result, it is likely that the true benefit of the physician in triage has been underestimated in this study.

Secondly, we compared the 6-month period before and the 6-month period after our intervention. Although the demographic information provided through the surveys was similar in both groups no perfectly matched control exists for comparison.

Furthermore, we used an additional faculty physician to staff the triage area. It is certainly possible that an additional physician working in the main part of the ED could have reproduced the benefits demonstrated in this study. We assume that because we, like many EDs, deal with multiple patients in our waiting room during the busiest times of day, the effects would not have been the same.

Our low response rate to the patient satisfaction survey is another limitation, with survey respondents representing $2.7 \%$ of all ED visits for the year and only $16 \%$ of those surveyed. Nevertheless, the response rate was similar across both groups.

Finally, this study does not address all of the potential benefits of physician in triage. For example, its direct effect on patient outcome or impact on radiology and laboratory studies were not addressed and could be the focus of further research endeavours.

\section{Conclusions}

In conclusion, physician in triage is a relatively novel approach utilized by some Emergency Departments to improve patient flow metrics. This model may also have the added benefit of enhancing patient satisfaction - in this study measured by improvement in Press Ganey ${ }^{\circledR}$ survey scores. 


\section{Conflicts of interest}

The authors declare that they have no competing interests.

\section{References}

[1] Derlet R, Richards J, Kravitz R. Frequent overcrowding in U.S. emergency departments. Acad Emerg Med. 2001 ; 8: 151-155. PMid: 11157291. http://dx.doi.org/10.1111/j.1553-2712.2001.tb01280.x

[2] Bernstein SL, Asplin BR. ED crowding: old problems, new solutions. Emerg Med Clin North Am. 2006; 24: 821-837. PMid: 16982341. http://dx.doi.org/10.1016/j.emc.2006.06.013

[3] Derlet RW, Richards JR. Overcrowding in the nation's emergency departments: complex causes and disturbing effects. Ann Emerg Med. 2000; 35: 63-68. http://dx.doi.org/10.1016/S0196-0644(00)70105-3

[4] Han JH, France Dj, Levin SR, et al. The effect of physician in triage on emergency department length of stay. J Emerg Med. J Emerg Med. 2010 Aug; 39(2): 227-33. PMid: 19168306. http://dx.doi.org/10.1016/j.jemermed.2008.10.006

[5] Partovi SN, Nelson BK, Bryan ED, et al. Faculty triage shortens emergency department length of stay. Acad Emerg Med. 2001; 8: 990-995. PMid: 11581086. http://dx.doi.org/10.1111/j.1553-2712.2001.tb01099.x

[6] Holroyd BR, Bullard MJ, Latoszek K, et al. Impact of a triage liaison physician on emergency department overcrowding and throughput: a randomized controlled trial. Acad Emerg Med. 2007; 14:702-708. PMid: 17656607. http://dx.doi.org/10.1111/j.1553-2712.2007.tb01864.x

[7] Terris J, Leman P, O’Connor N, et al. Making an IMPACT on emergency department flow: improving patient processing assisted by consultant in triage. Emerg Med J. 2004; 21: 537-541. PMid: 15333523. http://dx.doi.org/10.1136/emj.2002.003913

[8] Choi YF, Wong TW, Lau CC. Triage rapid initial assessment by doctor (TRIAD) improves waiting time and processing time of the emergency department. Emerg Med J. 2006; 23: 262-265. PMid: 16549569. http://dx.doi.org/10.1136/emj.2005.025254

[9] Crane PW, Schneider SM. The Effect of a Doctor in Triage on Press Ganey Patient Satisfaction Scores. Annals of Emergency Medicine, 50(3) Supplement 1, Sept 2007, S70 (abstract). http://dx.doi.org/10.1016/j.annemergmed.2007.06.373

[10] Subash F, Dunn F, McNicholl B, et al. Team triage improves emergency department efficiency. Emerg Med J. 2004; 21: 542-544. PMid: 15333524. http://dx.doi.org/10.1136/emj.2002.003665

[11] Rowe BH, Guo X, Villa-Roel C, et al. The role of triage liaison physicians on mitigating overcrowding in emergency departments: a systematic review. Acad Emerg Med. 2011 Feb; 18(2): 111-20. PMid: 21314769. http://dx.doi.org/10.1111/j.1553-2712.2010.00984.x

[12] Imperato J, Morris DS, Binder D, et al. Physician in triage improves emergency department patient throughput. Intern Emerg Med. 2012 Oct; 7(5): 457-62. PMid: 22865230. http://dx.doi.org/10.1007/s11739-012-0839-0

[13] Press Ganey® Associates Inc. Available from: http://www.pressganey.com/ Accessed 25 August 2013. 